\title{
The Influence of Persistence Factors on American Indian Graduate Students
}

\author{
Aislinn Heavy Runner-Rioux ${ }^{1}$, Frances L. O’Reilly ${ }^{2} \&$ John Matt ${ }^{2}$ \\ ${ }^{1}$ Kauffman \& Associates, Inc., USA \\ ${ }^{2}$ The University of Montana, USA \\ Correspondence: John Matt, University of Montana, Missoula, Montana, USA. Tel: 1-406-243-5586.
}

\author{
Received: April 17, $2018 \quad$ Accepted: May 3, $2018 \quad$ Online Published: May 15, 2018 \\ doi:10.5539/jel.v7n4p32 URL: https://doi.org/10.5539/jel.v7n4p32
}

\begin{abstract}
The underrepresentation of American Indian students continues to exist at the undergraduate and graduate levels of postsecondary education despite increases of American Indian student enrollment. The purpose of this quantitative study is to identify correlations between academic factors and graduate student persistence, as well as to understand how likely graduate degree completion is based on known academic factors for American Indian students. The analyses of the data included survey results, descriptive statistics, bivariate correlation, and multivariate regression. A sample of $n=63$ American Indian Graduate students represented 41 tribes and villages with over 32 unique tribal languages. The respondents indicated a challenge to balance graduate school, family and cultural responsibilities, however most felt a personal responsibility to complete their graduate degrees for their communities.

Although academic factors, American Indian programs, and self-awareness are not significant predictors of American Indian Graduate student persistence, the relationship between the independent variables and the dependent variable were statistically significant. Implications for academic institutions include strategic planning with American Indian representation throughout the entire process.
\end{abstract}

Recommendations for future research include further development of measurable concepts of indigenous theories and recognition of dual conclusions for American Indian and non-American Indian researchers.

Keywords: American Indian, Native American, Indigenous, education, higher education, degree completion, persistence, post-secondary, graduate degree, graduate school, masters, professional, doctorate, culture

\section{Introduction}

The number of American Indian students enrolled in higher education has increased consistently since the 1950s. The enrollment numbers for American Indian students in postsecondary education includes students enrolled in undergraduate, graduate, and professional programs. Despite these increasing trends, American Indian students remain the highest underrepresented minority in postsecondary institutions, representing less than $1 \%$ of enrolled students (U.S. Department of Education, National Center for Education Statistics [NCES], 2013). American Indian students have historically been and continue to be an underrepresented minority in mainstream higher education institutions across the United States (NCES, 2013).

The underrepresentation of American Indian students exists not only at the undergraduate level but also at the graduate level. Less than $0.5 \%$ of all students across the United States, enrolled in graduate programs - master and doctoral-identify as American Indian (NCES, 2013). The underrepresentation of American Indian students in graduate programs logically contributes to the underrepresentation of American Indian students earning graduate degrees (NCES, 2013).

\subsection{Purpose of the Study}

The purpose of this quantitative study was to 1) identify correlations between academic factors and American Indian graduate student persistence, and 2) to understand the probability of graduate degree completion for American Indian graduate students based on known academic factors. American Indian students enrolled in graduate programs, including master, doctoral, and professional, participated in this study. 


\subsection{Research Questions}

The following empirically based research questions were addressed in this study:

1) What factors contribute to American Indian graduate student persistence?

2) Do academic success factors relate to American Indian graduate student persistence?

3) Do American Indian academic programs relate to American Indian graduate student persistence?

4) Do student self-perceptions relate to American Indian graduate student persistence?

\section{Methodology}

\subsection{Research Design}

This study employed a survey design to understand the perceptions (Creswell, 2009) of American Indian graduate students and the persistence of graduate degree completion. The data were collected from a sample of American Indian graduate students attending graduate institutions across the United States. The cross-sectional survey collected data from a single point in time (Creswell, 2009). A web-based, self-administered questionnaire was used to collect the data.

\subsection{Population and Sample}

The population for this study consisted of American Indian graduate students currently enrolled in graduate programs at the time of the study. A multi-stage sampling design identified potential participants. The first stage identified and contacted individuals with large personal and professional networks of American Indians. A request was sent for assistance in disseminating the survey. The second stage utilized Facebook where a post was launched with a request to post and share the survey information. Upon receipt of the survey information, individuals had the opportunity to participate in the study as part of the non-probability sample.

The instrument in this quantitative study used modified questions from the qualitative Secatero study (2009). The qualitative study conducted by Secatero had a sample size of 32 participants. This study, using a quantitative method and virtual dissemination plan, garnered a larger response rate.

The purpose of this study is to contribute to the body of knowledge on American Indian student persistence and not to generalize to the American Indian graduate student population. Generalizability conflicts with the world-view of many American Indians where the uniqueness of individuals and tribes is honored and not the "blanket" approach to drawing conclusions. Although conclusions were garnered from this study, they are not intended to explain the experience of all American Indian graduate students.

\subsection{Variables}

This study utilized one dependent variable and a series of independent variables. In order to operationalize the concepts in this study, scales were used to construct the variables for the success factors; American Indian programs, self-perception, and persistence. Each of the scaled variables was constructed through the calculation of a Cronbach Alpha reliability score, included with each variable below.

\subsubsection{Dependent Variable}

The dependent variable, student persistence, was used to measure the effects of change based on the influence of the independent variables.

Student persistence. The continued mobility of students to the next level in their education-such as progressing through the levels in basic skills - or staying enrolled in college from term to term or year to year (Seppanen, 2007). This scaled variable was created from questions inquiring about how many times students had stopped and started school again and how many total terms had they taken off from graduate school (Alpha $=.753$ ).

\subsubsection{Independent Variables}

Academic success. Demmert (2001) identified the following as the common factors for success of Native American students: (a) family support, (b) cultural identity, (c) financial support, (d) academic skills, (e) mentors and supportive faculty, and (f) bicultural curriculum. This study, however, focused on all of Demmert's factors plus self-perception. Each factor was represented by a scaled variable based on questions that asked about different aspects of each factor.

Family support. This scaled variable was comprised of data from questions about; (a) the support a student receives from their family, and (b) if it is a high priority in social and spiritual wellbeing (Alpha $=.881$ ). 
Cultural identity. This variable was comprised of questions asking about a student's cultural identity and included questions about where the student was raised in terms of on or off a reservation, community support, participation in cultural activities, language, connection with other American Indian students, and returning home.

Financial support. This variable included data from questions on financial aid, loans, research or teaching assistantships, scholarships, fellowships, work-study, service-learning programs, and employment with hours worked per week. This scaled variable consisted of data from 11 questions (Alpha $=.733$ ).

Academic skills. This variable focused on academic preparation, previous degrees earned, GPA, applying to graduate school, entrance exams, and the importance of literacy skills. This scaled variable consisted of data from 18 questions (Alpha $=.751$ ).

Mentors. This variable was constructed from a question asking if the students had a graduate mentor.

Supportive faculty. This variable focused on the student's perception of how supportive the faculty and the staff were during the graduate school experience. The questions asked included rating how helpful faculty were, and if the student had a mentor. The scaled variable was comprised of data from 6 questions (Alpha $=.668$ ).

Academic programs. This variable focused on the student's perception of how supportive student service programs were during graduate school. The questions asked included rating how helpful student service providers were and if students had a mentor. The scaled variable was comprised of data from 10 questions $($ Alpha $=.789)$.

Self-perception. This factor was comprised of how American Indian students saw themselves in terms of self-esteem and self-efficacy and the elements of these constructs that contribute to persistence (Gloria \& Robinson Kurpius, 2001). Additionally, this variable included student perceptions of their abilities in a graduate school. The questions included physical, social, mental, and spiritual wellbeing along with the frequency of specific experiences, campus climate, and school academics. This scaled variable consisted of 45 questions $($ Alpha $=.842)$.

Physical well-being. This factor addressed how much of a priority different aspects of physical well-being were to American Indian graduate students. It included questions about hard work, endurance, diet, and exercise. This scaled variable consisted of 3 items (Alpha $=.804)$.

Social well-being. This factor addressed how much of a priority different aspects of social well-being were to American Indian graduate students. It included questions about family, communication, and leadership. This scaled variable consisted of 3 items (Alpha $=.718)$.

Mental well-being. This factor addressed how much of a priority different aspects of mental well-being were to American Indian graduate students. It included questions about intellectual growth, critical thinking, and decision-making. This scaled variable consisted of 3 items (Alpha $=.906)$.

Spiritual well-being. This factor addressed how much of a priority various aspects of spiritual well-being were to American Indian graduate students. It included questions about family, faith, sense of belonging, and religious activities. This scaled variable consisted of 4 items (Alpha $=.884)$.

Experience. This factor was comprised of questions asking about the frequency of certain experiences the American Indian graduate students may have had. These experiences included stress, depression, tiredness, social life, sickness, and other experiences. This scaled variable consisted of 9 items (Alpha= .602).

Campus climate. This factor was comprised of questions asking American Indian graduate students to rate the different aspects of campus climate. This variable included questions about the friendliness of students, diversity, and safety. This scaled variable consisted of 4 items $($ Alpha $=.955)$.

Academics. This factor was comprised of questions asking American Indian graduate students to rate their satisfaction with academics at their institution. It included questions about courses, work, creativity, and work groups. This scaled variable consisted of 6 items $($ Alpha $=.822)$.

\subsection{Demographics}

The survey participants ranged in age from twenty-two years old to fifty-five years old ( $\mathrm{n}=54 ; 9$ missing). The mean age of the participants in the study was thirty-four years old. The range of the ages of the participants indicated that approximately $30 \%$ of the participants were in their twenties; $45 \%$ were in their thirties; $17 \%$ were in their forties; and 8\% were in their fifties. Of the 54 survey participants, $42(78 \%)$ identified as female and 9 $(17 \%)$ identified as male. The remaining $5 \%(n=3)$ selected "other" for gender and reported as follows: gender 
fluid; non-binary/Two Spirit; and transgender, Two Spirit.

The survey participant's marital status ( $\mathrm{n}=54 ; 9$ missing) showed, $45 \%$ were single, $41 \%$ were married, $9 \%$ were divorced, and 5\% selected "other" and reported common law, domestic partnership, or in partnership. Of the 54 respondents, approximately half (48\%) reported having children; of this half, $19 \%$ had one child, $27 \%$ had two children, $27 \%$ had three, $19 \%$ had four, and $8 \%$ had five or more children. The final demographic question from the survey inquired about employment; $80 \%$ reported they were currently employed.

Additional demographic questions focused on American Indian characteristics. These characteristics included tribal affiliation, tribal language, fluency of language, location they were raised, and participation in tribal events. The survey participants $(\mathrm{n}=63)$ represented 41 tribes.

Table 1. Forty-one participating tribes

\begin{tabular}{lll}
\hline Aaniih (Gros Ventre) & Aleut & Arapaho \\
Assiniboine & Blackfeet & Cherokee Nation \\
Cherokee Nation of OK & Cheyenne River Sioux & Chippewa-Cree \\
Choctaw Nation of OK & Colville Conf. Tribes & Crow \\
Diné (Navajo) & Eastern Shoshone & Fort Peck Assiniboine \\
Gila River Indian Comm. & Akimel O'odham & Tohono O'odham \\
Gros Ventre & Kiowa & Southern Cheyenne \\
Arapaho & Lumbee Tribe of NC & Metis \\
Nez Perce Tribe of Idaho & Northern Cheyenne & Pascua Yaqui Tribe \\
Chippewa-Cree & Sac \& Fox & Ioway \\
Sault Ste. Marie Chippewa & Seneca Nation of Indians & Shoshoe-Bannock \\
Spokane & St. Regis Mohawk Tribe & Sisseton Wahpeton Oyate \\
Taíno (U.S. Caribbean & Tuscarora & White Earth \\
Yakama & Conf. Salish \& Kootenai & \\
\hline
\end{tabular}

Along with understanding the tribal affiliation of survey participants, the languages affiliated with these reported tribes were important to include. The survey participants $(n=63)$ reported the following 31 tribal languages: Aaniiih, Anishinaabemowin, Arawakan, Assiniboine, Bannock, Baxoje, Blackfeet, Chahta, Cheyenne, Choctaw, Cree, Crow, Dakotah, Diné Bizaad, Eastern Shoshone, Kiowa, Kootenai, Lakota, Mi'kmaq, Mohawk, Nakona, Navajo, Nimipuutimt, Nselxcin, O’odham Ńeo'oki?, Salish, Shoshone, Sioux, Spokane Salish, Taíno, and Unangan.

The survey included a question about the participants speaking fluency of their tribal language and the fluency of other languages. A total of 54 responses were collected on the fluency of the tribal languages as follows: $60 \%$ $(\mathrm{n}=33)$ reported they were non-fluent, $20 \%(\mathrm{n}=11)$ reported they understood the language but did not speak it, $7 \%(n=4)$ were semi-fluent, $3 \%(n=2)$ indicated they could carry on a conversation, and $5.6 \%(n=3)$ were fluent in their native language.

Fifty-five participants responded to questions about the participant's childhood: $38 \%$ reported being raised on a reservation or tribal community, $18 \%$ were raised off of a reservation, $24 \%$ were raised in an urban location, and $20 \%$ were raised in multiple locations.

Additionally, participants were asked about their involvement in tribal events. A total of 55 responses were received, of which $84 \%$ indicated they do participate in tribal events. The participants shared the tribal events they have participated in which are listed in Appendix A. Some of the listed events were duplicated in name only. The diversity of tribes needs to be acknowledged in this study, for example powwows, the most common answer from the participants in this study, may differ in meaning and have unique characteristics from tribe to tribe.

The results of the bivariate correlation signified a weak and non- statistically significant relationship between the dependent variable and the independent variables. The correlation coefficients for the independent variables were as follows: family (.212), financial (-.180), academic (-.161), faculty (.047), programs (.101), self (.167), physical (.245), social (.274), mental (.201), spiritual (.300), experience (.181), campus (.102), and academics (-.034). The correlation between persistence and spiritual well-being was the only significant relationship $(\mathrm{p}<.05)$.

Moderate correlations were found between American Indian programs and self-awareness (.690), physical well-being (.460), social well-being (.534), mental well-being (.590), spiritual well-being (.463), and experience (.555), while campus climate was a robust correlation (.883). All of the correlations between American Indian 
programs and the listed independent variables above were statistically significant $(\mathrm{p}<.01)$. Robust correlations were found between family and physical well-being (.820), social well-being (.905), mental well-being (.900), spiritual well-being (.801), and experience (.718). These correlations were also found to be statistically significant $(\mathrm{p}<.01)$.

\subsection{Multivariate Linear Regression}

The second phase in the analysis for this study involved a multivariate linear regression. The analysis allowed for the exploration in the data to account for the variability of a dependent variable when the influence of independent variables is known. This study addressed the hypotheses by understanding the amount of variance of American Indian graduate student persistence when the influence of success factors, American Indian programs, and self-perception can be measured.

A regression analysis was conducted on the dependent variable, persistence, with each of the independent variables stated in the hypotheses. An evaluation of linearity was performed using an assessment of a correlation matrix and scatter plots. The regression coefficients are presented in Table 2.

Table 2. Multiple regression analysis of perceptions of persistence on success factors, American Indian programs, and self-perception

\begin{tabular}{lllll}
\hline Independent variable & $\boldsymbol{\beta}$ & Beta & $t$ & $p$ \\
\hline Family support & .038 & .023 & .137 & .891 \\
Financial support & -.169 & .114 & -1.478 & .147 \\
Academic skills & -.091 & -.134 & -.693 & .493 \\
Faculty support & .077 & .121 & .479 & .635 \\
Amer. Indian prog & .032 & .045 & .109 & .914 \\
Self-perception & -.043 & -.042 & -.208 & .836 \\
Physical well-being & .151 & .121 & .695 & .491 \\
Social well-being & .224 & .140 & .671 & .506 \\
Mental well-being & -.053 & -.028 & -.158 & .875 \\
Spiritual well-being & .234 & .226 & 1.284 & .207 \\
Experience & .140 & .108 & .586 & .561 \\
Campus climate & -.101 & -.155 & -.494 & .624 \\
School academics & -.106 & -.069 & -.402 & .690 \\
\hline
\end{tabular}

$\mathrm{R}^{2}=.218, \mathrm{~F}(13,39)=65.981, \mathrm{p}=.620$.

The full regression model accounts for $21.8 \%$ of the variance in American Indian graduate student persistence. The results of the regression analysis failed to reject the null hypothesis in all three accounts.

\section{Research Conclusions}

The foundations of student departure were explored through Tinto's work over a course of forty years. Tinto (1972) identified many causal factors of student departure: academic difficulty, adjustment, goals, uncertainty, commitments, finances, integration and community membership, incongruence, and isolation. Tinto's model was derived from an adaptation of Durkheim's theory of suicide (1897); student departure was a form of suicide where it was the inability of students to not adapt to the institution, as well as a lack of support from the institutions (1972).

Tinto further developed the Model of Institutional Departure indicating academic difficulty, failure to identify goals, and failure to integrate into the culture of the institution contributed to students leaving academia. A key assumption in this model was the "cultural suicide" and adaptation of the institution culture (Tinto, 1993). The respondents in this study, current American Indian graduate students, indicated their culture remained with them through language, family, tribal activities, and considerations of returning to their home community after graduation.

The respondents in this study indicated specific tribal activities they maintained while in graduate school: year round or seasonal ceremonies, powwows, Native American Church, sweat lodge, Sundance, traditions, first kills/berry picking, longhouse ceremony, Chinook Dance, beadwork, dressmaking, harvest dinners, and fall encampment. The respondents also reported extensive cultural responsibilities: conducting ceremonies, continuity of heritage, community Sundance ceremony, care for sick relatives, community outreach, transportation, and keeper of spiritual items and songs. These tribal activities, cultural responsibilities, language, and priority of family are evidence of cultural continuity. This evidence is a direct argument against Tinto's 
assumptions of "cultural suicide" and a supportive measure of Tierney's argument (1999) of minority differences of cultural adaptation.

This study provided evidence the American Indian graduate students did not sacrifice their own culture; however no clear indicators existed regarding whether or not the institutions supported and valued the students' American Indian culture. The responses reinforced Tierney's initial study (1999) and peripheral agreement of confidence, cultural identity, and institutional recognition, through questions about self-confidence in ability to complete a graduate degree, various indicators of participation in cultural activities, and fulfilling cultural responsibilities. The responses to questions about campus climate indicated the institutions were average or below average for friendliness of students, campus diversity, tolerance of diversity, campus safety, and caring students. Although some of these measures are not directly about the institution, they do represent the perceptions of the American Indian graduate students and the descriptions of campus climates where the institutions have a lack of cultural support for American Indian graduate students.

The cultural protective factors identified by HeavyRunner and Marshall (2003) that contributes to American Indian student resilience (spiritualty, family strength, elders, ceremonial rituals, oral traditions, tribal identity, and support networks) were fully present in this study of American Indian graduate students. These factors were evident through American Indian graduate student perceptions of faith, belief systems, and sense of belonging being a high spiritual priority; family was a high social and spiritual priority along with high family support; multiple examples of ceremonial traditions and cultural responsibilities; tribal identity through tribe and language, and social networks of on and off campus relationships. These protective factors had strong relationships indicated through robust correlations and statistical significance (family and physical wellbeing (.820), social wellbeing (.905), mental wellbeing (.900), spiritual wellbeing (.801), and experience (.718)).

The grounded theory on tribal college student persistence (HeavyRunner-PrettyPaint, 2009) asked two key questions: (a) What is it like for tribal college students to manage the integration of academic, social, and cultural responsibilities?, and (b) How do community and college memberships influence educational persistence for tribal college students? In this study, similar to HeavyRunner-Pretty Paint's (2009) study, the students were asked about how they balance graduate school, family, and cultural responsibilities. The most common responses indicated family; graduate school was for their communities; prioritizing culture and school first; prayer and self-care; and a supportive family and community. These responses addressed why American Indian graduate students need to balance these responsibilities and how they balanced these responsibilities. One respondent from this study stated,

My family is very supportive, and does not demand a lot of me so that I can focus on school. I take my community responsibilities and graduate work in equal measure, keeping in mind that my work is for my community, not for myself.

The survey responses also address the second question from the grounded theory on tribal college student persistence (HeavyRunner-PrettyPaint, 2009). The American Indian graduate students in this study reported that balance was not easy, very difficult, challenging, and constantly feeling like they were failing. The student responses also indicated they just kept doing it, sacrifices, one day at a time, understanding it is a blessing and a curse, swinging back and forth like a pendulum, and still trying to find a balance. These responses paralleled HeavyRunner-PrettyPaint's (2009) theory as the most helpful to students not giving up.

The responses in this study also supported the model of Secatero (2009) American Indian graduate student success. The four components of the model - physical, mental, emotional, and spiritual well-being - were directly used to understand self-perception of American Indian graduate students in the Secatero study. These aforementioned specific measures [physical, mental, emotional, spiritual wellbeing] resulted in a weak relationship with persistence as it was measured for this study; however, when correlations were analyzed, these four measures had significant, robust relationships with family.

Overall, the strength of this study was the practical significance to understand the experience of American Indian graduate students in pursuit of earning graduate degrees. This study contributed in three, notable ways: (a) a confirmation of early studies on student persistence that did not account for cultural continuity and unique experiences of minority students; (b) providing further evidence of the importance of culture, relationships, and a responsibility to community as influential factors of American Indian student persistence; and (c) generating the need for further investigation into persistence for American Indian graduate students. This study provided further evidence and knowledge to understand the unique experience of American Indian graduate students enrolled in graduate degree programs. 


\section{Implications for Institutions}

Academic institutions need to specifically address the shortcomings in support and promotion of American Indian culture for American Indian students. The support and promotion of American Indian culture needs to include opportunities for American Indian students to experience the acceptance of diversity, and every opportunity other non-indigenous students have. Historically, efforts and resources have been allocated for these purposes; however, the change needs to originate from the American Indian students themselves.

The disconnect happens when direct efforts for American Indian students is prompted by the institution and does not include American Indian students from the origination. The key of this disconnect is the perspective of the institution, and not that of American Indian students. Concerted efforts to improve campus climate for American Indian students need to include the American Indian students throughout the entire process, from development to implementation.

The development of strategic plans with American Indian students involved in the planning and implementation will ensure the inclusion of American Indian students. The perspective of American Indian students will result in these efforts and resources aligning with what works for American Indian students and not perceived solutions. The collaboration between the institution and American Indian students will promote a culturally responsive effort to support American Indian student persistence.

\section{References}

Creswell, J. W. (2009). Research design: Qualitative, quantitative, and mixed methods approaches (3rd ed.). Thousand Oaks, CA: SAGE Publications, Inc.

Demmert, W. (2001). Improving academic performance among Native American students: A review of the research literature. Charleston, WV: ERIC Clearninghouse on Rural Education and Small Schools.

Gloria, A. M., \& Robinson Kurpius, S. E. (2001). Influences of self-beliefs, social support, and comfort in the university environment on the academic nonpersistence decisions of American Indian undergraduates. Cultural Diversity and Ethnic Minority Psychology, 7(1), 88-102. https://doi.org/10.1037/1099-9809.7.1.88

HeavyRunner, I., \& Marshall, K. (2003). Miracle survivors: Promoting resilience in Indian students. Tribal College, 14(4), 15.

HeavyRunner-PrettyPaint, I. (2009). Miracle survivor (Pisatsikamotaan): An Indigenous theory on educational persistence grounded in the stories of Tribal college students (Doctoral dissertation). Retrieved from https://conservancy.umn.edu/handle/11299. /50897

Secatero, S. (2009). Beneath our sacred minds, hands and hearts: Stories of persistence and dissertation. University of New Mexico. Retrieved from http://gradworks.umi.com/33/68/3368075.html

Seppanen, L. (2007). Summary of empirically tested theoretical perspectives in the literature on community and technical college student atsistence/success. Retrieved at http://citeseerx.ist.psu.edu/viewdoc/download;jsessionid=7F5E1D79800667B0D384F294569521FA?doi=1 0.1.1.617.3878\&rep=rep1\&type $=$ pdf

Tierney, W. G. (1999). Models of minority college-going and retention: Cultural integrity versus cultural suicide. Journal of Negro Education, 68(1), 80-91. https://doi.org/10.2307/2668211

Tinto, V. (1972). The effect of college proximity on rates of college attendance. Retrieved from ERIC database. (ED074888).

Tinto, V. (1993). Leaving college: Rethinking the causes and cures of student attrition. Chicago, IL: The University of Chicago Press.

U.S. Department of Education, National Center for Education Statistics. (2013). The Condition of Education (NCES 2013-037). Retrieved from http://nces.ed.gov/pubs2013/2013037.pdf

\section{Appendix A}

\section{Respondents List of Cultural Activities in Which They Participated}

American Indian Society of Washington, D.C. events; annual pow wow; at-large member events; basketball; ceremonies; ceremonies and powwows; ceremonies and celebrations; ceremonies and community events; ceremonies, powwows, tribal council meetings; ceremonies and traditions; community events, feasts, powwows, volunteer work; community feasts and student events; community pow-wows, give-away announcer, pow-wow 
advisor, and Sun Dance; district meetings and celebrations; elections and Labor Day festival; fall encampment and work with THPO office; traditional community gatherings, local gatherings, harvest dinners, powwows, winter dances; Labor Day festival, Longhouse ceremonies, Chinook Dances, Mul-Chu-Tha (annual rodeo and fair) and heritage center events; Native American Church; powwows, seasonal ceremony, cultural events; powwows, tribal ceremony, sweat lodge; powwow in tribal communities, community graduation; powwow, Round Dance, sweat, beadwork and dress making; powwow and sweat lodge; powwows; powwows and social gatherings, events related to tribal college and tribal political events; powwows, ceremonies, NAC, Kiowa Gourd Clan, O-Ho-Mah Lodge; powwows, name givings, celebrations, Round Dances, first kills/berry picking/fishing rights; religious ceremonies, powwows; seasonal ceremonies and intertribal powwows; Sun Dance, tribal events in the state; sweat lodges and OKAN; traditional Blackfeet and Sun Dance, powwow; and year-round ceremonies (sweats, big-drum).

\section{Copyrights}

Copyright for this article is retained by the author, with first publication rights granted to the journal.

This is an open-access article distributed under the terms and conditions of the Creative Commons Attribution license (http://creativecommons.org/licenses/by/4.0/). 